\title{
Indigenismo, antropología y testimonio en el Perú: \\ rupturas, ampliaciones y plataformas de representación
}

\section{Eduardo Huaytán Martínez}

Purdue University

\section{RESUMEN}

Este artículo sostiene que los primeros testimonios en el Perú están ligados al trabajo antropológico de las décadas de 1960 y 1970, y al intento de la narrativa indigenista por ampliar sus formas de representación. La hipótesis planteada es que el testimonio, como espacio de diálogo entre las ciencias sociales y las humanidades, fue a partir de 1970 una plataforma que promovió la representación de sujetos no considerados protagónicos anteriormente: afrodescendientes y especialmente mujeres. De tal forma, el abanico de protagonistas se amplió más allá de las fijaciones de la antropología culturalista y narrativa indigenista por el hombre indígena del Ande.

\section{PALABRAS CLAVE}

Indigenismo, antropología, narrativa indigenista, testimonio, representación, afrodescendientes, mujeres.

\section{ABSTRACT}

This article suggests that the first testimonies in Peru are linked to the anthropological work of the 1960s and 1970s, and the indigenous narrative's attempt to expand the forms of representation. The proposed hypothesis is that the testimony as a space for dialogue between the Social Sciences and Humanities, since 1970 was a platform that promoted the representation of subjects previously not considered leading: African descent and especially women. Thus, the range of actors is expanded beyond the fixation of culturalist anthropology and indigenous narrative with indigenous man walk. 


\section{KEY WORDS}

Indigenism, anthropology, indigenous narrative, testimony, representation, African-descent, women.

La tradición de la narrativa testimonial es de larga data en el Perú y continúa gestionándose desde diferentes lugares de enunciación: literatura, antropología, feminismo, sociología, historia oral, periodismo. En años recientes, el referente más relevante es el gran acervo de 17 mil testimonios gestionados desde la instancia de la Comisión de la Verdad y Reconciliación (CVR). A pesar de este vigoroso corpus podría parecer extemporáneo abordar el testimonio tomando en cuenta el desinterés que la crítica tomó respecto del artefacto testimonial a mediados de la década de 1990'. Como lo resume Fernández Benítez: «es importante resaltar que lo que entró en crisis fueron los testimonial studies y no la producción de testimonios» ${ }^{2}$. Pero incluso, como acota Juan Zevallos, durante los años del debate del testimonio el corpus testimonial peruano y sudamericano estuvo marginalizado en beneficio de un conjunto de testimonios centroamericanos hipercanonizados ${ }^{3}$. El propósito de este artículo no es volver al debate planteado hace dos décadas y que podría resumirse en el análisis de la tensa relación entre oralidad/escritura, documentalismo/ficcionalización, testor/gestor, política/estética. Más bien, propongo una lectura del proceso histórico de los primeros testimonios en el Perú en paralelo al trabajo de la antropología y la narrativa indigenista.

La antropología en Latinoamérica se profesionalizó en las primeras décadas del siglo XX. Carlos Iván Degregori y Pablo Sandoval proponen lo que Manuel Marzal afirmaba implícitamente; esto es, que la antropología en el Perú es creación y producto del indigenismo y «es necesario por tanto ubicar los inicios de la disciplina sobre ese trasfondo» ${ }^{4}$. En esa misma lógica, Henri Favre propone que «Si no existen indigenistas que no sean también antropólogos, tampoco existen antropólogos que no sean indi-

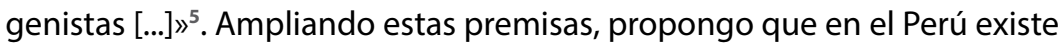
una íntima relación entre narrativa indigenista, antropología y testimonio. En primer término porque la matriz de esos tres proyectos discursivos es

1 El debate teórico sobre el testimonio, fundamentalmente centroamericano, está muy bien sintetizado en Testimonio hispanoamericano. Historia, teoría, poética (1992), de Elzbieta Sklodowska, el número 36 de la Revista de Crítica Literaria Latinoamericana dedicado enteramente al testimonio (1992) y The Real Thing. Testimonial Discourse and Latin America (1996) editado por Georg Gugelberger.

2 Fernández Benítez 2010: 67.

3 Zevallos 1998: 243.

4 Degregori y Sandoval 2008: 29.

5 Favre 1997: 118. 
el indigenismo como proyecto político e ideológico. En segundo término, la antropología, la narrativa indigenista y el testimonio se encuentran emparentados por el afán discursivo de dar cuenta de comunidades secularmente excluidas, especialmente las del Ande. En otras palabras, en estos tres proyectos la variable que los articula es la representación del indígena y su problemática, aunque, como se podrá apreciar luego, el testimonio supera el molde indigenista y dará cuenta de otros actores invisibilizados por aquella matriz: afrodescendientes y principalmente mujeres.

\section{Imaginación, simulacros y realidades antropológicas}

Una de las críticas a la narrativa indigenista, quizá la más relevante, fue que siempre estuvo profundamente desvinculada de su referente de representación y de las formas expresivas que este referente producía. Es decir, el único elemento que correspondía al universo indígena era el espacio y los personajes ficcionalizados ${ }^{6}$. La reformulación de esta polémica no tendrá lugar con el neoindigenismo u otras modalidades narrativas, sino a partir del trabajo interdisciplinario del testimonio; es decir, con el aprovechamiento de técnicas provenientes de la antropología, específicamente el trabajo etnográfico y la literatura de rasgos realistas. Como resultado de esta dinámica interdisciplinaria, además del referente, se suma el sujeto que inmerso en la cultura de aquel referente ${ }^{7}$. Esta mediación promueve no solo, como ya se ha dicho, un tránsito de la oralidad a la escritura en el texto testimonial mismo; sino la ruptura con una obra de marcados rasgos ficcionales, como la narrativa indigenista, a otra de ciertas marcas de factualidad, como la narrativa testimonial, por la presencia de un sujeto identificable en la realidad.

Sin embargo, el horizonte común de la narrativa indigenista y el testimonio es el ejercicio de una imaginación antropológica ${ }^{8}$. Asumo este término como la reproducción de la práctica y los códigos antropológicos para producir un discurso ficcional o factual. El ejecutor de la imaginación antropológica no necesariamente ha transitado por la profesionalización

6 Cornejo Polar 1980: 66.

7 Si aquella mediación le hace justicia a la voz traída de la oralidad, implica un análisis que escapa los límites de este artículo y del pesimismo de la crítica del testimonio centroamericano. En el canon testimonial peruano se hallan mediaciones sumamente interesantes que promovieron un espacio de diálogo ciertamente horizontal. Pienso, por ejemplo, en Cinturón de castidad. La mujer de clase media en el Perú (1979), conjunto de tres testimonios de mujeres mediados por Maruja Barrig.

8 Fass Emery, citada por López-Baralt, define imaginación antropológica como la conjunción de antropología y literatura: «[...]un fenómeno de largo alcance que abarca el primitivismo surrealista, el negrismo, el indigenismo de la primera mitad del siglo, el prolífico género testimonial que comenzó en los sesenta y el modernismo de la cultura popular de la novela transcultural» (López-Baralt 2005: 31). 
de la carrera. En el caso de la narrativa indigenista el narrador simula, en esencia, el discurso del antropólogo, porque la antropología fue el único discurso capaz de analizar y narrar con autoridad lo «autóctono» o, mejor aún, al Otro. Como lo expuso González Echevarría: «La antropología le da a los novelistas los instrumentos metodológicos, la retórica o el discurso para poder estar ahí y afuera al mismo tiempo» ${ }^{9}$. La diferencia en relación con el testimonio estriba en que no es un simulacro, sino una realidad antropológica. Como modo de representación, en el testimonio el ejercicio antropológico se hace práctica, ya que el gestor testimonial se acerca a un sujeto anclado en la realidad para mediar su historia de vida. Si la narrativa indigenista y al testimonio están emparentados por el hecho de ser producidos a partir de un proceso interdisciplinario, de connotaciones antropológico-literarias, en el testimonio la imaginación antropológica es un ejercicio verificable, pues gestor testimonial ejecuta un trabajo de características etnográficas que le otorga un claro perfil antropológico: relación cotidiana con el testimoniante, ejecución de entrevistas semiestructuradas, documentación, grabaciones, transcripciones, etc. En suma, la narrativa testimonial y la literatura indigenista son impulsadas por una imaginación antropológica que subyace a su producción y que en el caso del testimonio se hará práctica real y no simulacro.

\section{El Perú desde el cristal de las ciencias sociales y la intensifi- cación de la imaginación antropológica}

Para Cornejo Polar, las ciencias sociales empezaron a cubrir campos que antes la literatura consideraba suyos:

Ha habido un larguísimo periodo en el cual la literatura era el camino real para conocer el Perú. [...] llega un momento en que las mejores imágenes del Perú, las imágenes más convincentes, más globalizadas, comienzan a derivar de las ciencias sociales muy nítidamente, $y$ por consiguiente todo ese impulso por conocer al Perú a través de la literatura un poco pierde piso ${ }^{10}$.

Cornejo Polar apunta agudamente cómo las ciencias sociales afinaron la representación que no se lograba con la literatura e incluso a través de la crítica literaria, pero su sentido de representación, al menos en la afirmación citada, solo alude a una cara de esta: el ejercicio mimético de la realidad, por el contrario, no problematiza el nivel político del término («hablar por») y tampoco cómo es que la literatura reaccionó ante el embate de los científicos sociales. 
A partir de la década de 1970, las ciencias sociales, en particular la antropología, no solo descentraron el lugar privilegiado de la literatura sino hicieron que esta reaccione reformulando sus modos de producción y representación. En otras palabras, ante la avanzada del saber y la práctica antropológica para narrar el Perú de manera más aguda, se produce un consecuente desplazamiento exterior y reacción creativa de la literatura. Esta se adapta a los soportes y formas de la metodología etnográfica para finalmente crear discursos innovadores dentro del canon peruano del siglo XX. El resultado final es una intensificación de la imaginación antropológica y una ampliación de las comunidades a representar, pero siempre desde un estatuto ficcional. Dos casos paradigmáticos en la narrativa peruana de la década de 1970 e inicios de 1980 son las novelas Canto de sirena (1977), de Gregorio Martínez, y Las tres mitades de Ino Moxo (1981), de César Calvo ${ }^{11}$. Estas novelas, en clave antropológica, quebraron los parámetros habituales de producción. Fundamentalmente, se hicieron a base de entrevistas, documentación (incluso fotografía) y trabajo de campo de tipo etnográfico, pero son publicadas en los límites de la narrativa ficcional. En el caso de Martínez y Calvo, consciente o inconscientemente, asumieron del reto propuesto por las ciencias sociales e intentaron recurrir a su metodología para alcanzar una representación innovadora que amplificaba los rostros de la comunidad nacional —afrodescendientes en la novela de Martínez y comunidades selváticas en el caso de Calvo-y que ya no era posible a través de procedimientos literarios convencionales ni bajo el paradigma de la narrativa indigenista clásica. Por el otro lado y en sentido inverso, los científicos sociales se vieron motivados a publicar antropología en clave literaria, esto es, testimonios como narraciones de vida independizados de cualquier balance científico cuantitativo o cualitativo.

\section{Usos del testimonio en el Perú: recurso metodológico y recurso narrativo}

Los usos del testimonio también lo ubican en el ambiguo espacio entre las ciencias sociales y la literatura. Jacobo Alva Mendo realiza una clasificación del testimonio en el Perú a partir de su utilización: a) Como recurso metodológico: fuente primordial para validar las observaciones, intuiciones y conclusiones del investigador; b) Como recurso narrativo: narración

11 La pentalogía La guerra silenciosa, de Manuel Scorza, también podría incluirse en este grupo de novelas. Aunque Scorza no escapa al espacio del Ande, su obra también experimenta una mayor intensificación de la imaginación antropológica. Incluso el último Arguedas se vale del magma etnográfico para dar forma a El zorro de arriba y el zorro de abajo (1971). Es de notar que todas estas novelas mencionadas se publican a partir de la década de 1970. 
coherente, relato de vida de largo aliento, donde los informantes usualmente dan cuenta de una relación problemática con la modernidad ${ }^{12}$.

Como recurso metodológico, el testimonio fue una herramienta de las ciencias sociales, sobre todo de la antropología, para poder sustentar, con ejemplos «vivos» de «carne y hueso» sus hipótesis, sus propuestas de lectura de algún fenómeno sociocultural determinado; por ejemplo, el trabajo rural en las haciendas de antes de la reforma agraria y luego de ella, y sobre todo el proceso de migración que venía experimentando el país. En aquel contexto, fines de la década de 1950 e inicios de la década de 1960, se vive una gran transformación en los estudios de comunidades, en palabras de Ramón Pajuelo: «se busca dar cuenta más de los cambios que de las permanencias» ${ }^{13}$. La antropología se va desligando en cierta medida de una visión indigenista clásica y se apropia del testimonio como uno de sus recursos metodológicos.

En 1964, el Instituto de Estudios Peruanos (IEP) ejecuta el «Proyecto de estudios de cambios en pueblos permanentes». El proyecto, dirigido por Matos Mar y William White, hizo trabajos de campo en los valles costeños de Virú, Moche y Chancay; y los valles serranos del Mantaro, Urubamba, entre otros ${ }^{14}$. Los resultados más fructíferos estuvieron en el valle de Chancay, que «se convierte a lo largo de la década [...] en un importante laboratorio de investigación y enseñanza, bajo la dirección de Matos Mar y con estrecha colaboración entre los investigadores del IEP y de San Marcos» ${ }^{15}$. Los resultados de este proyecto se vieron reflejados en libros, artículos, folletos mimeografiados y tesis universitarias. Precisamente, uno de los productos decantados de este proyecto fue el primer testimonio peruano: Erasmo. Yanacón del valle del Chancay, de Matos Mar y Jorge A. Carbajal, publicado en 1974, pero cuyo trabajo de campo y registro testimonial fue realizado una década antes, en $1963^{16}$. El segundo testimonio en el Perú, no vinculado con el proyecto del IEP, en el cual también repara Alva Mendo, es $L a$ villa de Santiago del Cao, ayer. Narración de don Enrique, de José Sabogal Wiesse, publicado en 1974 en la revista mexicana Anuario Indigenista.

\footnotetext{
12 Alva Mendo 2003: 65.

13 Pajuelo 2001: 144.

14 Pajuelo 2001: 144.

15 Pajuelo 2001: 44.

16 Un texto a tomar también en cuenta es Las barriadas de Lima: 1957, de José Matos Mar. Este libro se publicó por primera vez en 1966, nueve años después de realizado el trabajo de campo. La segunda edición se publicó en 1977, 11 años después de la primera edición. Lo novedoso de esta segunda edición es un apartado final con 18 testimonios de pobladores. Resulta sintomático la inclusión de estas narraciones de vida, y diagnostica, una vez más, el tránsito del testimonio de herramienta metodología a considerarlo en su valor intrínseco como narrativa, en su especificidad. Aunque en este caso los testimonios son apéndice de un largo estudio de antropología urbana.
} 
El caso de Erasmo. Yanacón del valle del Chancay evidencia claramente cómo la antropología produce uno de los primeros testimonios en nuestro país. Además, en un mismo objeto testimonial se observa el tránsito de concebirlo como recurso metodológico - fue producto del trabajo de campo del proyecto del IEP-, para luego tomar forma de recurso narrativo y ser inscrito en el circuito editorial en clave literaria con valor narrativo en sí mismo. En 1974 también se publicó como recurso narrativo el testimonio de Saturnino Huillca bajo el titulo Huillca: habla un campesino peruano. El caso de este testimonio es diferente. Hugo Neira, como corresponsal de un periódico limeño, había cubierto por cuatro meses las movilizaciones campesinas en el Cusco en 1963. Un año después publicaría todos sus envíos bajo el nombre de Cusco: tierra o muerte (1964). En este contexto conoció al sindicalista Saturnino Huillca, cusqueño, analfabeto y monolingüe quechuahablante, fundador de uno de los primeros sindicatos rurales en el sur andino. Huillca: habla un campesino peruano se haría en 1974 con el premio Casa de las Américas en el rubro de Testimonio y sería publicado ese mismo año en La Habana. A diferencia del testimonio gestionado por Matos Mar y Carbajal, este proyecto incluye el primer testimonio de una mujer. Aquel breve relato es el de Agustina Huaquira Mamani, la esposa de Saturnino. Este hecho constata que el testimonio desde su inicio propone una ampliación representacional de otros actores sociales que no cabían en otros formatos discursivos.

Como recurso narrativo, los testimonios fueron ganando su propio peso a mediados de la década de 1970 . Se realizan testimonios ya no como parte metodológica de un proyecto de investigación antropológica, sino para ser publicados en tanto historias de vida. De este modo, el testimonio transita hacia los límites de la antropología para adentrarse en los terrenos de la literatura, pero mostrando un mayor margen representacional. Uno de estos testimonios iniciales es Autobiografía de Gregorio Condori Mamani (1977). Gestionado por los antropólogos Ricardo Valderrama y Carmen Escalante, este proyecto no solo incluye el testimonio del cusqueño Gregorio, sino también el de su esposa Asunta ${ }^{17}$. Sin embargo, es necesario acotar que las voces tanto de Agustina y Asunta aparecen en tono menor, en especial la de la primera, opacadas e invisibilizadas por el protagonismo que recae en la voz testimonial de sus esposos y por la agenda misma de los gestores. Agustina y Asunta son mujeres del Ande sin participación política explícita; sus testimonios no se proyectan como

17 Los testimonios de Saturnino Huillca y Gregorio Condori han sido analizados por Jesús Díaz Caballero, a la luz del proyecto nacionalista del gobierno militar de Juan Velasco Alvarado (1968-1975). 
historias épicas de reivindicación social y crítica a las estructuras del poder. En particular, sus testimonios son el reconocimiento de una vida de sufrimiento. Agustina y, sobre todo, Asunta nos narran las historias de una de las tantas supervivientes de un sistema signado por la opresión étnica, racial y de género. No todas tienen la misma capacidad para testimoniar ni para luchar contra los sistemas que las oprimen. Agustina Huaquira y Asunta Quispe son las Otras de Rigoberta Menchú y Domitila Barrios.

En un segundo momento, al cierre de la década de 1970, se produce un mayor protagonismo de las mujeres a partir de los testimonios colectivos circunscritos a la agenda feminista; estos son los casos de los 14 testimonios de Ser mujer en el Perú (1977), producidos por las periodistas y feministas Esther Andradi y Ana María Portugal, y los tres testimonios de Cinturón de castidad. La mujer de clase media en el Perú (1979), por la periodista de tendencia feminista Maruja Barrig. En este corpus el espacio de enunciación ya no se ve restringido a una agenda masculina de los gestores del proyecto testimonial. Entonces, se amplía el campo de representación de las mujeres en dos sentidos: primero, se ha desplazado totalmente la figura masculina que ocupaba un espacio mayor y central de enunciación; como consecuencia, hay un protagonismo único y, por tanto, mayor de las mujeres; segundo, este protagonista se hace colectivo: las mujeres y la construcción de su narrativa personal forman un grupo relativamente numeroso y heterogéneo.

Por otro lado, es necesario tomar en cuenta que si bien algunos de estos testimonios nacen de la propia actividad antropológica, otros nacen de áreas próximas o no tanto: historia, periodismo, feminismo o la combinación de estos. El caso sui géneris es el de José Sabogal Wiesse, hijo del pintor indigenista, quien fue un ingeniero agrónomo, claro está con aficiones antropológicas. En parte es indudable el origen del testimonio en el quehacer antropológico, aunque también se gestionan testimonios desde diferentes frentes de conocimiento. En todos los casos se hace posible desde una imaginación antropológica, la cual motiva el encuentro con un relato desde la diferencia. Asimismo, como ya se dijo, el paso del testimonio, de herramienta metodológica a recurso narrativo, se dio dentro del mismo espacio de las ciencias sociales. Finalmente, el testimonio recién comenzará a interesar a los especialistas en literatura a partir de la década de 1980 , continuará en la de 1990 y en la primera década de $2000^{18}$.

18 Algunos de los testimonios gestados por especialistas en literatura son Don Joaquín. Testimonio de un artista popular andino (1982), de Mario Razzeto; Jaime Guardia. Charanguista (1985), de Manuel Larrú; Soy señora. Testimonio de Irene Jara (2000), de Francesca Denegri. 


\section{El testimonio y las ampliaciones de la plataforma represen- tacional}

Degregori y Sandoval ${ }^{19}$ afirman que el periodo indigenista en el Perú estuvo marcado por el paradigma del mestizaje y su concepción de las identidades de manera estática y esencialista. En ese sentido:

A la antropología latinoamericana la impulsó la nostalgia [...] de (re) construir un Nosotros homogéneo. A lo largo de la década del 1960, la contundencia de la realidad incidió cada vez más en la disciplina, hasta hacerla desbordar los marcos de esa primera etapa indigenista y exploradora, enmarcada [...] dentro del culturalismo, en la cual el folclor era el tema privilegiado, las comunidades el ámbito central y el trabajo de campo sacralizado como rito de iniciación [...]. Ese desborde se da por acumulación, conforme nuevos ámbitos, temas e influencias se incorporan a la antropología.

Desbordado los límites del indigenismo, en las últimas décadas del siglo XX se inicia otro paradigma en el cual existe la conciencia de vivir en una nación no solo bicultural, sino pluricultural. El testimonio peruano, dentro de este trayecto, se presenta como superación de las dualidades estáticas y esencialistas del indigenismo clásico y la antropología indigenista, y más bien evidencia en sus relatos de vida la representación de identidades dinámicas, heterogéneos en constante reelaboración. María Teresa Grillo, a partir de la propuesta teórica de Cornejo Polar, propone a la narrativa testimonial peruana como una narrativa heterogénea, vale decir, como un discurso que es producto de la relación dinámica y conflictiva de dos espacios culturales (occidentales y tradicionales) la mayoría de veces antagónicos ${ }^{20}$. Además, el testimonio en el Perú abre el campo de representación hacia otras comunidades que no habían sido abordadas ni integradas a la nación, y que incluso mantenían un mayor grado de subalternidad en relación con las comunidades andinas.

Asimismo, Cornejo Polar, en consonancia con lo expuesto por Degregori y Sandoval, advierte que al iniciarse el siglo XX se da un cambio de perspectiva: cada vez con mayor insistencia se estudia y se recopila la poesía y los relatos de «los indios modernos». El iniciador de esta filología de la literatura viva es Adolfo Vienrich (Azucenas quechuas, 1905), quien sería el precursor de los estudios folclóricos. Además, Cornejo Polar propone una genealogía de lo que llama estudios de filología viva; esto es, estudios etnográficos de recopilación de literatura oral. El investigador enumera tres periodos: a) El ciclo iniciado por Azucenas quechuas culmina con Canto 
kechwa publicado por José María Arguedas en 1938; b) El segundo periodo, tributario del primero, produce recopilaciones y traducciones de la literatura quechua y tendrá una intencionalidad fuertemente artística. El propio Arguedas sería una figura central; c) El tercer periodo se caracteriza por criterios de fidelidad antropológica y lingüística, «se amplía el campo de atención a las literaturas amazónicas y se consolida, como género, el relato testimonial» ${ }^{21}$.

La clasificación de Cornejo Polar describe el camino de una vertiente del trabajo etnográfico a lo largo del siglo XX. Propone un inicio caracterizado por el estudio de tipo folclorista - antropología culturalista en términos de Degregori-, en el marco de un mundo moderno costeño frente a un mundo rural andino, que encuentra como punto máximo de resolución al paradigma mestizo. Es decir, entre fines de la década de 1960 y mediados de la de 1970, con la consolidación de las ciencias sociales, la antropología se desligará del molde indigenista culturalista: «Por la vía del énfasis en el conflicto y la transformación, o por la del énfasis en la diversidad cultural, la antropología indigenista y culturalista de los primeros tiempos llegaba a sus límites, desbordada por la realidad ’22 $^{22}$. La antropología encontrará su propia especificidad y abrirá años posteriores su campo de estudio -estudios urbanos de barriadas, etnohistoria-y aparecerán diferentes rostros de la nación; por ejemplo, se abre hacia los estudios amazónicos, pero a la vez esta apertura multicultural se verá limitada por el paradigma marxista ${ }^{23}$.

En el trabajo antropológico surge una vertiente marxista que será hegemónica y que nunca tendrá sintonía con la antropología de los actores de la cultura que de modo temprano se planteaba como posibilidad y que el testimonio supo acoger de inmediato. Desde esta perspectiva: «El trabajo de la antropología culturalista fue percibida con investigaciones académicas "apolíticas" »" ${ }^{24}$. El desborde de la antropología indigenista y la irrupción del testimonio representaba la promesa de otro paradigma que superase la oposición excluyente de tradición/modernidad. Los testimonios eran claro y didáctico ejemplo de cómo las identidades no eran estáticas ni esenciales, sino que los testimoniantes en sus relatos de vida mostraban un juego de múltiples identidades. Lamentablemente, aquel

21 Cornejo Polar 1989: 125. Un texto fundamental de esta apertura hacia el mundo amazónico es La sal de los cerros. Una aproximación al mundo campa (1968), de Stefano Varese. Cornejo Polar no menciona este libro, sino el posterior La verdadera biblia de los cashinahua (1975), de Marcel d'Ans.

22 Degregori y Sandoval 2008: 39.

23 Degregori y Sandoval.

24 De la Cadena 2004: 210. 
temprano paradigma intercultural se vio frustrado por el lente marxista y tendría que esperar unas décadas. Degregori y Sandoval mencionan que algunos de los trabajos de Rodrigo Montoya, César Fonseca o John Murra fueron a contracorriente de esta perspectiva reduccionista ${ }^{25}$; pero Degregori y Sandoval no reparan en la veta testimonial, que apuntala, si bien desde una posición menos protagónica, la posición de una antropología del actor, importancia del relato de vida y del sustrato cultural como práctica cotidiana, y una perspectiva pluricultural que recién se podría desarrollar a partir de la última década del siglo XX.

En otras palabras, el testimonio no solo posará su mirada a ese gran otro, «el hombre indígena» de la narrativa indigenista y la antropología culturalista, que marca la agenda de ambas como proyectos de matriz indigenista; otras comunidades mucho más subalternizadas, que ni siquiera habían alcanzado a ser visibilizadas por las élites intelectuales progresistas en sus agendas investigativas, también ocuparon la atención del testimonio. Me refiero, por ejemplo, a la comunidad afrodescendiente y en general a grupos minoritarios o grandes mayorías en una posición de secular subordinación, como el de las mujeres. En relación con la narrativa testimonial, resulta revelador acotar cómo entre los primeros testimonios publicados en el Perú destaca la voz de un afrodescendiente, la figura de don Erasmo, en el testimonio gestado por Matos Mar y Carbajal. También ese mismo año, muy tímidamente y como apéndice, emerge la voz de Agustina Huaquira Mamani, esposa de Saturnino Huillca, líder sindical cusqueño protagonista del testimonio gestado por Hugo Neyra. Tres años después hallamos la voz de Asunta Quispe Huamán en Gregorio Condori Mamani. Autobiografía (1977). Finalmente, cerrando la década de 1970 se publican los testimonios de mujeres urbanas en Ser mujer en el Perú (1977) y Cinturón de castidad. La mujer de clase media en el Perú (1979). El margen de representación de las mujeres, en estos dos casos, se abría ampliamente.

El testimonio, por sus mismas dinámicas internas de producción, hace inevitable y espontáneo la generación de mayores espacios de representación, y se convierte de este modo en una inusitada plataforma representacional que no había podido ser forjada ni por la literatura ni por la antropología en sus vertientes más tradicionales. En el Perú, desde su aparición se presenta como una gran narrativa democratizadora, al visibilizar y producir discursos emergentes: emerge la voz de un afrodescendiente - comunidad por lo demás poco tratada en la literatura y hasta ahora sin una tradición consolidada en las ciencias sociales-; por otro 
lado, emerge la voz de mujeres andinas, que hasta entonces habían tenido una reducida participación en las políticas representativas y que no había merecido atención de los discursos indigenistas y antropológicos ${ }^{26}$. Finalmente, emerge la voz de mujeres urbanas en los testimonios colectivos ya mencionados.

En definitiva, el testimonio rebasa los límites de la literatura indigenista y la antropología culturalista al amplificar y crear una plataforma representacional de base amplia. El testimonio en el Perú ya no solo se acerca al llamado indígena del Ande, sino a las comunidades afroperuanas, además de romper con una vocación masculinista y sumar la presencia de las mujeres. No obstante, este tránsito de apertura representacional se fue dando gradualmente y continúa gestándose la mayoría de veces desde una imaginación antropológica, que dialoga con otras ideologías subyacentes en el gestor o gestora testimonial. En este punto, es acaso plausible acuñar el término antropología testimonial, para definir aquel proceso discursivo que se vale de las herramientas de la antropología para exclusivamente producir relatos de vida en clave testimonial y no como herramienta metodológica. Pero, además, la antropología testimonial, impulso para la producción de testimonios, recibe influjos de otros discursos interiorizados en los gestores, como el marxismo, en el caso de Hugo Neira y su trabajo con Saturnino Huillca, y el feminismo, en el caso de Andradi-Portugal y Barrig y sus trabajos con mujeres urbanas, que finalmente serán decisivos para el resultado final de la representación.

26 A modo de ejemplo, no es complicado enumerar héroes masculinos indígenas en el canon de la narrativa indigenista: Rendón Huillca en Todas las sangres (1964), Rosendo Maqui y Benito Castro en El mundo es ancho y ajeno (1941), el estudiante Escobar en Yawar fiesta (1941), Héctor Chacón El Nictálope en Redoble por Rancas (1970). Por el contrario, no es tan sencillo mencionar a personajes femeninos con relevancia en la acción narrativa y en el devenir de las tramas. Una de las pocas imágenes de mujeres en un plano narrativo protagónico la propone Los ríos profundos (1958) en la protesta de las chicheras. El protagonismo femenino encuentra su personificación en doña Felipa. 


\section{REFERENCIAS BIBLIOGRÁFICAS}

ALVA MENDO, Jacobo (2003). «El testimonio oral en los Andes centrales. Travesías y rumor». En Gonzalo Espino Relucé (compilador). Tradición oral, culturas peruanas. Una invitación al debate. Lima: Fondo Editorial de la Universidad Nacional Mayor de San Marcos y Facultad de Letras y Ciencias Humanas.

ANDRADI, Esther y PORTUGAL, Ana María (1978). Ser mujer en el Perú. 1977. Lima: Tokapu Editores.

BARRIG, Maruja (1979). Cinturón de castidad. La mujer de la clase media en el Perú. Lima: Mosca Azul Editores.

CALVO, César (1981). Las tres mitades de Ino Moxo y otros brujos de la Amazonía. Iquitos: Proceso Editores.

CORNEJO POLAR, Antonio (1980). La novela indigenista. Literatura y sociedad en el Perú. Lima: Lasontay.

(1989). La formación de la tradición literaria en el Perú. Lima: Centro de Estudios y Publicaciones.

DE LA CADENA, Marisol (2004). Indígenas mestizos. Raza y cultura en el Cusco. Lima: Instituto de Estudios Peruanos.

DEGREGORI, Carlos Iván y SANDOVAL, Pablo (2008). Saberes periféricos. Ensayos sobre la antropología en América Latina. Lima: Instituto Francés de Estudios Andinos e Instituto de Estudios Peruanos.

DENEGRI, Francesca (2000). Soy señora. Testimonio de Irene Jara. Lima: Instituto de Estudios Peruanos, Flora Tristán y El Santo Oficio.

DÍAZ CABALLERO, Jesús (1996). «Para una lectura del etno-testimonio peruano de los años setenta». En José Antonio Mazzotti y Juan Zevallos, (coordinadores). Asedios a la heterogeneidad cultural. Libro de homenaje a Antonio Cornejo Polar. Lima: Asociación Internacional de Peruanistas y Lluvia Editores.

FAVRE, Henri (1997). El indigenismo. México D. F.: Fondo de Cultura Económica.

FERNÁNDEZ BENITTEZ, Hans (2010). «"The moment of testimonio is over": problemas teóricos y perspectivas de los estudios testimoniales». En Íkala, Revista de Lenguaje y Cultura, nro. 24, pp. 47-71.

GONZÁLEZ ECHEVARRÍA, Roberto (1998). Mito y archivo. Una teoría de la narrativa latinoamericana. México D. F.: Fondo de Cultura Económica.

GRILLO, María Teresa (2006). «Discursos de la nación escindida. Una aproximación al testimonio en el Perú (Gregorio Condori Mamani. Autobiografía y Huillca: habla un campesino peruano)». Tesis para optar el grado de magíster. Universidad Nacional Mayor de San Marcos. 
GUGELBERGER, George (editor) (1996). The Real Thing: Testimonial Discourse and Latin America. Durham: Duke University Press.

LARRÚ, Manuel (1988). Jaime Guardia, charanguista. Lima: Instituto Nacional de Cultura.

LÓPEZ BARALT, Mercedes (2005). Para decir al Otro. Literatura y antropología en nuestra América. Madrid: Iberoamericana / Vervuert.

MARTíNEZ, Gregorio (1977). Canto de sirena. Lima: Mosca Azul Editores.

MAZAL, Manuel (1981). Historia de la antropología indigenista: México y Perú. Lima: Fondo Editorial de la Pontificia Universidad Católica del Perú.

MATOS MAR, José (1977). Las barriadas de Lima, 1957. Lima: Instituto de Estudios Peruanos.

MATOS MAR, José y CARBAJAL, Jorge A. (1974). Erasmo. Yanacón del valle de Chancay. Lima: Instituto de Estudios Peruanos.

NEYRA, Hugo (1964). Cuzco: tierra o muerte. Lima: Populibros Peruanos.

(1974): Habla un campesino. La Habana: Casa de las

Américas.

PAJUELO, Ramón (2001). «Imágenes de la comunidad. Indígenas, campesinos y antropólogos en el Perú». En Carlos Iván Degregori (editor). No hay país más diverso. Compendio de antropología peruana. Lima: Red para el Desarrollo de las Ciencias Sociales en el Perú.

SKLODOWSKA, Elzbieta (1992). Testimonio hispanoamericano. Historia, teoría, poética. Nueva York: Peter Lang Publishing.

VALDERRAMA, Ricardo y ESCALANTE, Carmen (1977). Gregorio Condori Mamani. Autobiografía. Cusco: Centro de Estudios Rurales Andinos Bartolomé de las Casas.

VARESE, Stefano (1973). La sal de los cerros. Una aproximación al mundo campa. Lima: Retablo de Papel Ediciones.

ZEVALLOS Aguilar, Juan (1998). «A propósito de Andean Lives, Gregorio Condori Mamani y Asunta Quispe Huamán. Apuntes sobre la hipercanonización y negligencias de la crítica del testimonio». En Revista de Crítica Literaria Latinoamericana, nro. 48, pp. 241-248. 